Pacific Journal of Mathematics

PROJECTIONS ONTO THE SUBSPACE OF COMPACT 


\title{
PROJECTIONS ONTO THE SUBSPACE OF COMPACT OPERATORS
}

\author{
E. O. THORP
}

Introduction. The purpose of this paper is to establish the following theorem.

THEOREM. Suppose $U$ and $V$ are Banach spaces and that there are bounded projections $P_{1}$ from $U$ onto $X$ and $P_{2}$ from $V$ onto $Y$. Then there are no bounded projections from the space of bounded operators on $U$ into $V$ onto the closed subspace of compact operators, in the following cases:

1. $X$ is isomorphic [1] to $\ell^{p}, 1 \leq p<\infty ; Y$ is isomorphic to $\ell^{q}$, $1 \leq p \leq q \leq \infty$ or $c_{0}$ or $c$.

2. $X$ is isomorphic to $c_{0} ; Y$ is isomorphic to $\iota^{\infty}, c_{0}$ or $c$.

3. $X$ is isomorphic to $c ; Y$ is isomorphic to $\iota^{\infty}$.

Notation. If $X$ and $Y$ are Banach spaces, $[X, Y]$ is the set of bounded linear operators from $X$ into $Y . /^{\infty}$ is the set of bounded sequences with the sup norm.

A space $X$ is said to have a countable basis if there is a countable subset of elements of $X$, called a basis, such that each $x \in X$ is uniquely expressible as

$$
x=\sum_{i=1}^{\infty} \xi_{i} \varphi_{i}
$$

in the sense that

$$
\lim _{n \rightarrow \infty}\left\|x-\sum_{i=1}^{n} \xi_{i} \varphi_{i}\right\|=0 .
$$

If $X$ and $Y$ are spaces with countable bases $\left(\varphi_{i}\right)$ and $\left(\psi_{i}\right)$ respectively and $A$ is a bounded linear transformation from $X$ into $Y$, then $A$ can be represented by an infinite matrix $\left(a_{i j}\right)$, with

$$
A \varphi_{j}=\sum_{i=j}^{\infty} a_{i j} \psi_{i}
$$

[2]. In what follows, the basis used for $\ell^{p}$ will be given by $\varphi_{j}=$ $(0,0, \cdots, 0,1,0,0, \cdots)$ where there is a 1 in the $j$ th place and 0 elsewhere. Similarly for $\psi_{i}$. The matrix representations of operators will all be with respect to these bases.

Received April 29, 1959. The author thanks Professor Angus Taylor for proposing this problem and thanks both him and Professor Richard Arens for helpful discussions. 
Proof of the theorem. The details of the proof are given below only for $X=\ell^{p}, 1 \leq p<\infty$, and $Y=\ell^{q}, 1 \leq p \leq q<\infty$. The proof for the remaining pairs is similar and is indicated in a remark at the end.

Definition. Let $E$ be the function on $\left[\iota^{p}, \ell^{q}\right], 1 \leq p \leq q<\infty$, which sends an operator whose matrix is $\left(a_{i j}\right)$ into the operator whose matrix is $\left(a_{i j} \delta_{i j}\right)$, i.e. the non-diagonal matrix elements are replaced by zero and the diagonal elements are unaltered.

Lemma 1. $E$ is a projection with $\|E\|=1$, range the diagonal operators, and null-space the operators with $a_{i i}=0$, all $i$.

Proof. $E$ is additive and homogeneous as easily follows from [2]. $E^{2}=E$, and the characterization of the range and null-spaces are apparent.

From the chain

$$
\begin{aligned}
\infty>\|A\| & =\sup _{\|x\|_{p} \leq 1}\|A x\|_{q} \geq \sup _{j}\left\|A \varphi_{j}\right\|_{q} \\
& =\sup _{j}\left\|\sum_{i} a_{i j} \psi_{j}\right\|_{q} \geq \sup _{j}\left\|a_{j j} \psi_{j}\right\|_{q}=\sup _{j}\left|a_{j \jmath}\right| \\
& \geq \sup _{\Sigma\left|\xi_{i}\right|^{p} \leq 1}\left(\sum\left|a_{i i} \xi_{i}\right|^{p}\right)^{1 / p} \geq \sup _{|| x \|_{p} \leq 1}\left(\sum\left|a_{i i} \xi_{i}\right|^{q}\right)^{1 / q}=\|E A\|,
\end{aligned}
$$

where the last $\geq$ is by Jensen's inequality, we see that $E$ sends bounded operators into bounded operators and, further, $\|E\|=1$. Also

$$
\|E A\| \leq \sup _{j}\left|a_{j j}\right| \text {. }
$$

In fact,

$$
\|E A\|=\sup _{j}\left|a_{\jmath \jmath}\right|
$$

because

$$
\|E A\| \geq \sup _{j}\left\|E A \Phi_{\jmath}\right\|=\sup _{j}\left|a_{j \jmath}\right|
$$

LEMMA 2. The mapping $\gamma$ from the set of diagonal operators onto $\iota^{\infty}$ defined by $\gamma\left(a_{i i}\right)=\left(a_{11}, a_{22}, \cdots\right)$ is an isometry which carries the compact diagonal operators onto $c_{0}$.

Proof. That $\gamma$ is an isometry from the diagonal operators onto $\ell^{\infty}$ follows from the previous observation that $\|E A\|=\sup _{j}\left|a_{j j}\right|$. Hence it suffices to show that the compact diagonal operators are exactly those with the additional condition $\lim _{i}\left|a_{i i}\right|=0$. This condition is necessary; 
otherwise for some $\varepsilon>0$ there is an infinite index set $I$ such that $\left|a_{i i}\right| \geq \varepsilon$ whenever $i \in I$. Then the bounded sequence $\left(\mathscr{P}_{i}\right)_{i \in I}$ would be carried into the sequence $\left(a_{i i} \psi_{i}\right)_{i \in I}$, which has no convergent subsequence, showing $\left(a_{i i}\right)$ is not compact. The condition is sufficient because, if $\|x\|_{p} \leq 1$ then

$$
\left(\sum_{i=1}^{\infty}\left|a_{i i} \xi_{i}\right|^{q}\right)^{1 / q} \leq\left(\sup _{i \geq n}\left|a_{i i}\right|\right)\|x\|_{q} \leq \sup _{i \geq n}\left|a_{i i}\right|
$$

and [2; Th. 2] applies. The last inequality follows from Jensen's inequality and our assumptions $p \leq q,\|x\|_{p} \leq 1$.

Lemma 3. Suppose $X$ is a Banach space with a closed subspace $\mathfrak{M}$ onto which there is a bounded projection $E$. Let $\mathfrak{R}$ be the null-space of $E$. Let $\mathfrak{s}$ be any closed linear manifold of $X$ such that if $f \in \mathfrak{S}$ then $f=g+h$, with $g \in \mathfrak{P} \cap \mathfrak{M}$ and $h \in \mathfrak{P} \cap \mathfrak{N}$. Then, given any bounded projection $F$ onto $\mathfrak{F}, E F$ is a bounded projection onto $\mathfrak{W} \cap \mathfrak{M}$ such that $\|E F\| \leq\|E\|\|F\|$.

The proof is an obvious modification of [3; Lemma 1.2.1].

Let $\mathfrak{s}$ be the set of compact operators, $\mathfrak{M}$ the set of diagonal operators, $E$ the projection of Lemma 1 , and $\mathfrak{R}$ its null-space. In order to apply Lemma 3 it remains to show: given any compact operator $f, E f$ and $f-E f$ are compact. $E f$ is compact because, if $f$ is compact,

$$
\lim _{n}\left\|\sum_{i=n}^{\infty} a_{i j} \psi_{i}\right\|=\lim _{n}\left(\sum_{i=n}^{\infty}\left|a_{i j}\right|^{q}\right)^{1 / q}=0
$$

uniformly in $j$. This implies $\lim _{n}\left|a_{n n}\right|=0$, which shows that Ef is compact. Hence $f-E f$ is compact.

To prove the theorem for $\left[/^{p}, /^{q}\right], 1 \leq p \leq q<\infty$, assume there is a bounded projection $F$ from $\left[/^{p}, /^{q}\right]$ onto $\mathfrak{F}$. By Lemma 3 , the restriction of $E F$ to $\mathfrak{M}$ is a bounded projection from $\mathfrak{M}$ onto $\mathfrak{M} \cap \mathfrak{P}$. By Lemma 2 there must be a corresponding bounded projection from $>^{\infty}$ onto $c_{0}$. This contradicts [4; Cor. 7.5]. For the remaining $X$ and $Y$ pairs of the main theorem, the proof is similar except that the existence of expressions for $\|A\|$ in terms of the matrix coefficients (e.g., see [5]) makes some of the work simpler.

Next we extend the theorem to $[U, V]$. Let $\tilde{E}$ be the function on $[U, V]$ defined by $\tilde{E} f=P_{2} f P_{1}$ for all $f$ in $[U, V] . \tilde{E}$ is linear and homogeneous and bounded. $\tilde{E}^{2} f=P_{2}\left(P_{2} f P_{1}\right) P_{1}=P_{2} f P_{1}=\tilde{E f}$ so $\tilde{E}$ is a projection. The range of $\tilde{E}$ is the set of operators $g$ such that $P_{2} g P_{1}=$ $g$ and is isomorphic with $[X, Y]$. The null-space of $\tilde{E}$ is the set of operators $h$ such that $P_{2} h P_{1}=0$. If $Q_{i}$ is the projection $I-P_{i}$, the 
decomposition $f=g+h$ is given by

$$
f=\left(P_{2}+Q_{2}\right) f\left(P_{1}+Q_{1}\right)=\underbrace{P_{2} f P_{1}}_{g}+(\underbrace{P_{2} f Q_{1}+Q_{2} f P_{1}+Q_{2} f Q_{1}}_{h}) .
$$

If $f$ is compact, so are $g$ and $h$. We apply Lemma 3 with $X=$ $[U, V], \mathfrak{M}$ the range of $\tilde{E}, \tilde{E}$ acting as the projection $E$ of that lemma, and $\mathfrak{P}$ the set of compact operators from $U$ to $V$. The conclusion is that if there were a bounded projection $F$ from $X$ to $\Re$, the restriction of $\tilde{E} F$ to $\mathfrak{M}$ would be a bounded projection from $\mathfrak{M}$ onto $\mathfrak{P} \cap \mathfrak{M}$, contradicting our result for $[X, Y]$.

REMARK. The problem of finding a bounded projection onto the compact operators is trivial when all the bounded operators are compact. This happens, for example, for $\left[\ell^{p}, \ell^{q}\right], \infty>p>q \geq 1,[2$, p. 700], or $p=\infty, q=1$, and for $\left[c_{0}, \ell^{q}\right],\left[c, \ell^{q}\right], \infty>q \geq 1$. Whether there exists a pair of normed spaces with a bounded proper projection from the bounded operators onto the compact operators seems to be unknown.

\section{REFERENCES}

1. S. Banach, Theorie des opérations linéarès Warsaw, 1932.

2. L. W. Cohen and N. Dunford, Transformations in sequence spaces, Duke Math. J., 3 (1937), 689-701.

3. F. J. Murray, On complementary manifolds and projections in spaces $L_{p}$ and $/ p$, Trans. Amer. Math. Soc., 41 (1937), 138-152.

4. R. S. Phillips, On linear transformations, Trans. Amer. Math. Soc., 48 (1940), 516-541.

5. A. E. Taylor, Introduction to functional analysis, John Wiley and Co., (1958).

University of California, Los ANgeles, California 


\section{PACIFIC JOURNAL OF MATHEMATICS}

\section{EDITORS}

David Gilbarg

Stanford University

Stanford, California

F. H. Brownell

University of Washington

Seattle 5, Washington
A. L. Whiteman

University of Southern Californıa Los Angeles 7, California

L. J. PaIge

University of California

Los Angeles 24, California

\section{ASSOCIATE EDITORS}
E. F. BECKENBACH
T. M. CHERRY
D. DERRY

E. HEWITT
A. HORN
L. NACHBIN
M. OHTSUKA

H. L. ROYDEN

M. M. SCHIFFER
E. SPANIER

E. G. STRAUS

F. WOLF

\section{SUPPORTING INSTITUTIONS}

\author{
UNIVERSITY OF BRITISH COLUMBIA \\ CALIFORNIA INSTITUTE OF TECHNOLOGY \\ UNIVERSITY OF CALIFORNIA \\ MONTANA STATE UNIVERSITY \\ UNIVERSITY OF NEVADA \\ NEW MEXICO STATE UNIVERSITY \\ OREGON STATE COLLEGE \\ UNIVERSITY OF OREGON \\ OSAKA UNIVERSITY \\ UNIVERSITY OF SOUTHERN CALIFORNIA
}

\author{
STANFORD UNIVERSITY \\ UNIVERSITY OF TOKYO \\ UNIVERSITY OF UTAH \\ WASHINGTON STATE COLLEGE \\ UNIVERSITY OF WASHINGTON \\ AMERICAN MATHEMATICAL SOCIETY \\ CALIFORNIA RESEARCH CORPORATION \\ HUGHES AIRCRAFT COMPANY \\ SPACE TECHNOLOGY LABORATORIES \\ NAVAL ORDNANCE TEST STATION
}

Mathematical papers intended for publication in the Pacific Journal of Mathematics should be typewritten (double spaced), and the author should keep a complete copy. Manuscripts may be sent to any one of the four editors. All other communications to the editors should be addressed to the managing editor, L. J. Paige at the University of California, Los Angeles 24, California.

50 reprints per author of each article are furnished free of charge; additional copies may be obtained at cost in multiples of 50 .

The Pacific Journal of Mathematics is published quarterly, in March, June, September, and December. The price per volume (4 numbers) is $\$ 12.00$; single issues, $\$ 3.50$. Back numbers are available. Special price to individual faculty members of supporting institutions and to individual members of the American Mathematical Society: $\$ 4.00$ per volume; single issues, $\$ 1.25$.

Subscriptions, orders for back numbers, and changes of address should be sent to Pacific Journal of Mathematics, 2120 Oxford Street, Berkeley 4, California.

Printed at Kokusai Bunken Insatsusha (International Academic Printing Co., Ltd.), No. 6, 2-chome, Fujimi-cho, Chiyoda-ku, Tokyo, Japan.

PUBLISHED BY PACIFIC JOURNAL OF MATHEMATICS, A NON-PROFIT CORPORATION

The Supporting Institutions listed above contribute to the cost of publication of this Journal, but they are not owners or publishers and have no responsibility for its content or policies. 


\section{Pacific Journal of Mathematics}

\section{Vol. 10, No. $2 \quad$ October, 1960}

Maynard G. Arsove, The Paley-Wiener theorem in metric linear spaces ........

Robert (Yisrael) John Aumann, Acceptable points in games of perfect

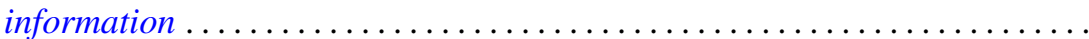

A. V. Balakrishnan, Fractional powers of closed operators and the semigroups generated by them ... . . . . . . . . . . . . . . . . . . . . . . . . . . . . 419

Dallas O. Banks, Bounds for the eigenvalues of some vibrating systems . . . . . 439

Billy Joe Boyer, On the summability of derived Fourier series . . . . . . . . . . . 475

Robert Breusch, An elementary proof of the prime number theorem with

remainder term ...................................

Edward David Callender, Jr., Hölder continuity of $n$-dimensional

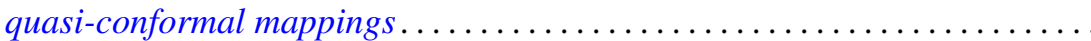

L. Carlitz, Note on Alder's polynomials ......................... 517

P. H. Doyle, III, Unions of cell pairs in $E^{3} \ldots \ldots \ldots \ldots \ldots \ldots \ldots \ldots \ldots \ldots \ldots \ldots . \ldots 21$

James Eells, Jr., A class of smooth bundles over a manifold . . . . . . . . . . . . 525

Shaul Foguel, Computations of the multiplicity function . . . . . . . . . . . . . . 539

James G. Glimm and Richard Vincent Kadison, Unitary operators in

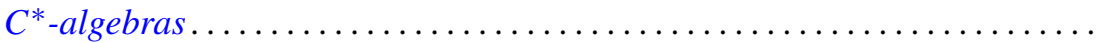

Hugh Gordon, Measure defined by abstract $L_{p}$ spaces . . . . . . . . . . . 557

Robert Clarke James, Separable conjugate spaces ....................

William Elliott Jenner, On non-associative algebras associated with bilinear forms

Harold H. Johnson, Terminating prolongation procedures

John W. Milnor and Edwin Spanier, Two remarks on fiber homotopy type .

Donald Alan Norton, A note on associativity . .

Ronald John Nunke, On the extensions of a torsion module.

Joseph J. Rotman, Mixed modules over valuations rings . . . . .

A. Sade, Théorie des systèmes demosiens de groupoï des . .

Wolfgang M. Schmidt, On normal numbers . .

661

Berthold Schweizer, Abe Sklar and Edward Oakley Thorp, The metrization of

statistical metric spaces

John P. Shanahan, On uniqueness questions for hyperbolic differential

equations

A. H. Stone, Sequences of coverings

Edward Oakley Thorp, Projections onto the subspace of compact operators

L. Bruce Treybig, Concerning certain locally peripherally separable spaces

Milo Wesley Weaver, On the commutativity of a correspondence and a

permutation

David Van Vranken Wend, On the zeros of solutions of some linear complex

differential equations. 